\title{
Research on the Network Course Construction and Practice of Chinese and Foreign Music History in Colleges and Universities
}

\author{
Jie Zhao \\ Jiangxi Teachers College, Jiangxi, Yingtan, China, 335000
}

Keywords: Colleges and Universities; Chinese and Foreign Music History; Network Curriculum Construction; Practice

\begin{abstract}
With the rapid development of modern Internet information technology, the development and construction of high-quality network courses has become a crucial issue in Internet education. This paper starts from the necessity of the construction of the network course of Chinese and foreign music history in colleges and universities, analyzes the existing problems in the construction of the online course of Chinese and foreign music history, and puts forward the practice of constructing the network course of Chinese and foreign music history program.
\end{abstract}

\section{Introduction}

The basic course of the traditional course is the reconstruction of the traditional network information environment, which has the basic characteristics of sharing, openness, collaboration, interaction and autonomy. In the network course model, the modules of the teaching activities should be effectively integrated and the teaching level should be broadened. The construction of "the history of Chinese and foreign music" in colleges and universities is of great practical significance to enhance the comprehensive ability of college students and promote the teaching reform. Therefore, we must rely on the Internet information technology, to actively explore the teaching activities, in practice, optimize the teaching mode and teaching strategies, update the teaching philosophy, and ultimately enhance the "Chinese and foreign music history" course teaching quality, build a scientific curriculum network structure.

\section{The Necessity of Network Course Construction in Chinese and Foreign Music History}

College students have innovative thinking and it must be based on a wealth of knowledge. The knowledge referred to a certain amount, but also refers to the quality of knowledge, "quality" is the scientific structure of scientific and rational arrangements, so the university curriculum is scientific and reasonable is worthy of study. If the lack of natural science and the infiltration of human knowledge, college students' knowledge and vision will be too narrow, it is difficult to build innovative thinking needs of the diversified knowledge system [1]. However, many colleges and universities in China still use the traditional teaching mode, so that students in a passive acceptance of the status, heavy "skills" light "art" teaching tend to become increasingly serious, the long run, it is difficult to shape the new era of qualified talent.

Therefore, we must build an online course as soon as possible, the use of modern teaching methods, the establishment of multimedia classrooms. The world is in constant development and change, a new era of college music teachers, should be dialectical materialism of the scientific world outlook, values and thinking mode to guide the music practice teaching. The traditional curriculum limits the students' horizons, only let the students understand some basic music theory and music structure of Chinese and foreign music history, understand the music from the height of "music culture", lack the ability of interdisciplinary connection with other disciplines, in the teaching practice to use other forms of art to prove their own point of view. "University of Chinese 
and foreign music history" network curriculum is the full consideration of the diversity of content, the form of multimedia and multi-angle and other aspects of the requirements of the new curriculum reform in the basic education to develop an integrated approach.

\section{The Current Problems in "Chinese and Foreign Music History" Network Curriculum Construction}

At present, there are serious loopholes in the curriculum of Chinese and foreign music history in major universities in China. Not only the course is single, it but also lacks of diversity, and structural rigidity, professional too strong. Although many music colleges have built a campus network at this stage, the network construction of the network course has also been rapid development, but many teachers still have a soft spot for the backward chalk + blackboard teaching mode, this and the new era background " Music history "teaching philosophy is contrary to each other. At present, the problems in the construction of online curriculum of Chinese and foreign music are concentrated in the following two aspects.

Ignore the Curriculum Performance. Chinese major colleges and universities in the "Chinese and foreign music history" network curriculum construction are mostly policy-driven, low teaching efficiency, attention to investment and technology, but also ignored the benefits and design, the network curriculum itself is not given great attention to the performance issues.

On the one hand, there are serious duplication of construction and waste of resources in the construction of "Chinese and foreign music history" network course. "The history of Chinese and foreign music" network construction of the lack of cooperation between colleges and universities, resource sharing degree to be improved, resulting in the existence of duplication of investment in hardware and software and secondary construction, in some basic music history courses have entered a lot of manpower and material resources. If the existing "Chinese and foreign music history" network curriculum resources can meet certain teaching needs, then in the absence of teaching investment and the low level of teachers, it should be through resources to reduce the cost of online courses, so that the effectiveness of online courses more on the floor. On the other hand, it is easy to produce "formatting" of course design. Because the Chinese and foreign music history network curriculum design is generally in accordance with the requirements of the policy, the structure and mode of the curriculum is too rigid, lack of diversity, it is difficult to fully reflect the nature of the discipline and curriculum characteristics. In addition, the lack of attention to the follow-up development of the network history of music history in colleges and universities has led to the slow pace of updating the network course.

Ignore the Learning Performance. There are some colleges and universities lack of knowledge of Chinese and foreign music history network courses, teaching research is not in-depth nature, resulting in a lot of online courses in the form and content of the lack of harmonization. The first is the abuse of technology; in the construction of Chinese and foreign music history network courses, the abuse of technology and do not ask the performance of the situation is widespread. In the design of network courses, if the technology beyond the needs of college students, which will not only bring inconvenience to the operation of teachers and college students, but also seriously affect the learning effect. The concept of Chinese and foreign music history network design is behind, many courses over-emphasis on the teaching content e analysis the scientific and rational design of learning environment and learning activities. The online course is a new type of teaching model learning is not limited to a certain location and time. In the absence of teacher guidance, the design of learning situations and learning activities is critical and will have a significant impact on the overall efficiency of efficiency. Finally, it is not teaching and learning organization and management, the prevalence of development research, light management applications. Many colleges and universities in the history of Chinese and foreign music history lack of research-based learning design and guidance to students. And the role of teachers is too simple, should be appropriate to change, not only to be reflected in the concept and awareness, more importantly, the need to implement the curriculum development and teaching practice. And at this stage is still a lack of scientific evaluation system and feedback system, many Chinese and foreign music history 
network courses are not on the student's learning process real-time record [2].

\section{The Practice of "Chinese and Foreign Music History" Network Course Construction}

Improve the Network Curriculum System through the Multimedia Network Technology. In the Internet environment, teaching resources to achieve the greatest degree of transmission and sharing. Cyberspace can effectively improve the teaching structure of Chinese and foreign music history, so that students can communicate with each other flexibly, and promote the diversification of teaching mode. Teachers should also keep pace with the times make full use of multimedia network technology to improve the network curriculum system. In the "Chinese and foreign music history" network course mode, teachers should be on the music teaching process of the various modules for organic integration. For example, combine the "Chinese and foreign music theory" and "Chinese and foreign music appreciation" together to comparatively analysis the music of each period to strengthen the understanding of students. At the same time, teachers should also expand the teaching space, guide students to query learning resources, to achieve self-learning. For example, in the "music theory based" teaching module, to lead students to use the Internet, to find a variety of learning materials to help learning materials and music resources, to enhance the enthusiasm of college students on the basis of learning to enhance the "Chinese and foreign music history" classroom teaching efficiency, and ultimately optimize the Chinese and foreign music history network course system.

Construct Network Teaching Materials and Create Situational Classroom. The construction of the network teaching materials should be with the People's Music Publishing House and other well-known publishers to synchronize the contents of the textbook to provide content-rich and functional diversity of classroom knowledge coaching, through high-end, advanced self-learning philosophy and inquiry learning philosophy, Master more knowledge, so as to effectively improve the academic performance and comprehensive ability. To build a scientific and sound three-dimensional network teaching materials, need to do four aspects of the work. First of all, we must do a good job research project to solve the conflict between content and form, deepen the curriculum reform at the same time and dilute the professional. Followed by good demonstration work, scientific design, step by step implementation, adequate with the advantages of multimedia, to develop a scientific teaching program, build a database. Once again to strengthen the training of university music teachers, from the essence of the three-dimensional teaching materials to play the function. The last point is to build a mutual aid teaching site, let it become teachers, students, editors and publishing units to communicate interactive and start teaching activities of the place. Use a variety of courseware resources and video files, vivid and intuitive analysis of the difficulties in teaching materials. Create a situation classroom, and effectively enhance the students in the history of Chinese and foreign music history of the special ability, so that the teaching experience of sufficient professors in the specified time, the integration of knowledge, induction course purification, teaching and review strategies, as much as possible to enhance the level of understanding and writing Ability to break through the difficulties to help students develop good learning habits, improve the overall quality [3].

Build a Network Teaching Platform to Strengthen the Teaching Interaction. The construction of the university "Chinese and foreign music history" network course is conform to the trend of the times, not only to promote college students to music learning and music literacy has important practical significance, but also the development of teaching ideas innovation is also essential. In the specific teaching time, we should regularly build the university "Chinese and foreign music history" network course. With the help of the Internet, the flexibility use the advantages of multimedia information technology, and vigorously build the organic teaching model, in the network teaching into the process of discipline development. Through the construction of network teaching platform, strengthen the teaching interaction. For example, in the university "Chinese and foreign music history" teaching process, teachers can be a period of music or music culture as a learning unit, in the network teaching platform design teaching activities and the layout of teaching tasks, so that students cooperation to explore, strengthen the common and exchange, to 
enhance the overall learning efficiency, and then teachers and then the corresponding evaluation of teaching activities.

Construct Targeted Modular Network Courses. The major colleges and universities to build "Chinese and foreign music history" network course in the process, the network course can be divided into three modules, targeted to start teaching. The first is the network Q \& A module, the Chinese and foreign music history learning and examination process which appeared in the difficult problems, to answer points. This module is designed for students to deal with learning difficulties, students can also ask questions, teachers to make a synchronous or asynchronous solution to the problem. Followed by a selection of test questions module, collecting the classic Chinese and foreign history of music history questions, enrich the type of questions. Provide exam questions, contest questions or representative of the motif for college students to learn reference. So that college students in strengthening their own foundation, combing important knowledge points on the basis of their own ability to test their own actual test, objectively measure their own history of Chinese and foreign music history, and purposefully learn from each other. The last is to set up a Kaoyan module, as professional examination counseling. So that experienced teachers or special teachers to the students for college entrance examination counseling. At present, the history of Chinese and foreign music is the major music college entrance examination of the compulsory subjects, with particular emphasis on the accumulation of basic knowledge. Therefore, in the Kaoyan module network courses should highlight the special lectures, so that combination of lectures make students master the problem-solving methods and techniques, analogy, improve learning efficiency [4].

\section{Conclusion}

To sum up, the teaching history of Chinese and foreign music history is becoming more and more serious, and the construction of network course is very necessary. However, there are still a lot of problems in the construction of online curriculum of Chinese and foreign music history, which is reflected in the neglect of curriculum performance and learning performance. Therefore, in the actual construction of the network course, we should improve the network course system through the multimedia network technology, construct the network teaching material and create the situation classroom and the network teaching platform, construct the targeted modular network course.

\section{References}

[1] Zhang Yaxin.Chinese "Chinese and foreign music history" network course construction thinking[J]. Literature and Art Life · Zhong Zhong, 2017, 12 (2): 230.

[2] Li Jun. College music teacher professional Chinese and foreign music education history teaching [J]. Audio-visual, 2015, 10 (5): 167-168.

[3] Dong Lin. From the Chinese and foreign music education awareness of Chinese future development of music education[J]. Northern music, 2016, 36 (2): 2.

[4] can be static. Chinese and foreign music history curriculum diversification teaching exploration and research [J]. Yellow River Voice, 2016, 15 (19): 41. 